\title{
Medical credit cards come under scrutiny
}

Published at www.cmaj.ca on Oct. 5

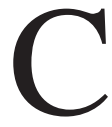

redit cards that can be used only for health care expenses are growing in popularity in the United States, a trend that is putting money in the pockets of medical professionals but may be hurrying patients down the road to personal bankruptcy.

Over the past three or four years, US financial institutions have begun partnering with health care providers to offer medical credit cards to people without health insurance or those who require services not covered by their insurance. It started out in just a few states, including Texas and North Carolina, and soon spread across the country.

Now, patients may find themselves receiving pitches for these cards such as Chase Health Advance or the Citi Health Card - in the offices of dentists, family physicians, chiropractors and cosmetic surgeons. One of the more popular cards, the GE Money CareCredit, is accepted by more than 125000 medical clinics.

"They kind of snuck onto the scene," says Craig Conway, a research professor with the University of Houston Law Center in Texas, who in 2009 wrote a paper about medical credit cards (www .law.uh.edu/healthlaw/perspectives/ 2009/(CC)\%20MedicalCards.pdf).

In his paper, Conway notes that US citizens spend about US\$294 billion annually on out-of-pocket medical expenses, a quarter of which they charge to standard credit cards. But an estimated 79 million people have trouble paying those expenses and, as a result, health care providers struggle to collect money owed to them. Health care medical cards thus become attractive to both patients, who may have already maxed out their other credit cards, and health care providers, who don't have to spend as much time and money collecting bills.

Though there is little downside for health care providers, there may be

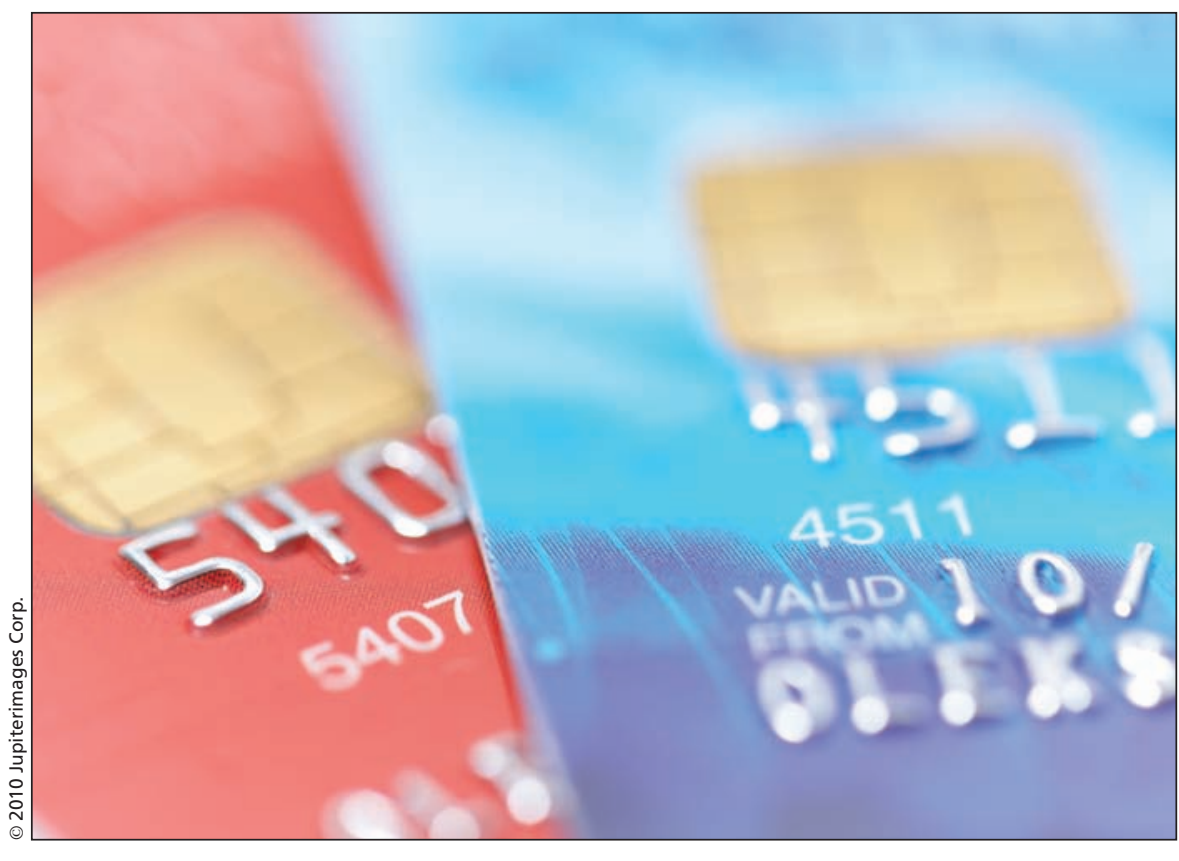

Medical credit cards often offer no-interest teaser rates for introductory periods, but interest rates baloon up to almost $30 \%$ for late payments.

significant risk for consumers. The cards offer no-interest teaser rates for introductory periods, but interest rates balloon up to almost $30 \%$ for late payments. In addition, health care providers receive rebates from financial institutions based on how much their patients charge to their cards, which critics claim has lead some providers to aggressively market the cards and recommend their use over other methods of payment.

In some states, a backlash against medical credit cards has already begun. In August, New York's attorney general, Andrew Cuomo, announced an expansion of an investigation into the "predatory lending practices" of medical centres pushing the cards. The investigation, launched after hundreds of complaints from consumers, had already found that some health care practices were using "fast-talking sales pitches to pressure and deceive" consumers, including seniors and vulnerable patients (www .ag.ny.gov/media_center/2010/aug/aug9 a_10.html).
In August 2009, Minnesota Attorney General Lori Swanson issued a consumer alert to warn patients that a trip to a clinic looking to "boost its bottom line" could result in a barrage of highpressure sales pitches (www.ag.state.mn .us/consumer/pressrelease/090812health carecreditcards.asp).

Patients may be more likely to fall for these pitches than they would be outside of a medical context, says Conway. "You go into the office thinking they are going to take care of you, and you may not be as sharp as you would be in other situations," he says. "They might not explain what the card is and just give you another form to fill out. Patients think they are supposed to fill it out."

According to Dr. Steffie Woolhandler, a medical professor at Harvard University in Boston, Massachusetts, doctors should not accept any type of credit card. Though their use ensures doctors receive payments, it is rarely in their patients' interests to accumulate more debt, says Woolhandler, who has studied 
the effects of illness and injury on personal bankruptcy rates (Health Aff 2006;25:w74-83).

"You'll get paid but heaven only knows what will happen to the consumer," says Woolhandler. "When people can't afford medical care, we ought to work with them to try to help them afford care, rather than put it on a credit card."

The advantages to health care practitioners, however, appear to make med- ical credit cards an option too attractive to resist. In the magazine Dental Economics, a dental practice consultant extolled the benefits to dentists of marketing dedicated health care credit cards, which include reducing the burden on front-desk staff to collect unpaid bills (www.dentaleconomics.com /index/display/article-display/122362 /articles/dental-economics/volume-86 /issue-3/features/health-care-credit-cards -can-increase-case-acceptance.html).
The cards also increase the likelihood of patients accepting treatments they would otherwise be unable to afford. "After all, would you rather have an [US] $\$ 800$ profit on [US] $\$ 2,000$ worth of dentistry or no profit if the patient simply cannot afford to have the treatment performed," the article states. "The answer is obvious!" — Roger Collier, CMAJ

DOI:10.1503/cmaj.109-3688 